\title{
Observations of Right-Moving Supercell Motion Forecast Errors
}

\author{
MATTHEW J. BUNKERS \\ NOAA/National Weather Service, Rapid City, South Dakota
}

(Manuscript received 12 September 2017, in final form 7 November 2017)

\begin{abstract}
Two shear-based supercell motion forecast methods are assessed to understand how each method performs under differing environmental conditions for observed right-moving supercells. Accordingly, a 573-case observational dataset is partitioned into small versus large values of environmental and storm-related variables such as bulk wind shear, convective available potential energy, mean wind, storm motion, and stormrelative helicity (SRH). In addition, hodographs are partitioned based on the tornado damage scale, as well as where the storm motion falls among the four quadrants. With respect to the 573-case dataset, the largest supercell motion forecast errors generally occur when the (i) observed midlevel (4-5 km AGL) storm-relative winds are either anomalously weak or strong, (ii) observed 0-3-km AGL SRH is large, (iii) supercell motion is fast, (iv) convective inhibition is strong, or (v) the surface-500-mb $(1 \mathrm{mb}=1 \mathrm{hPa}) \mathrm{RH}$ is low. Moreover, significantly tornadic supercells are biased $1.2 \mathrm{~m} \mathrm{~s}^{-1}$ slower and farther right of the hodograph than predicted by the Bunkers forecast method, but show very small bias for the modified Rasmussen-Blanchard method (though errors are slightly larger for this method). Conversely, the smallest errors occur when, relative to the overall sample, the (i) observed upper-level (9-10 km AGL) storm-relative winds are strong, (ii) supercell motion is slow or the mean wind is weak, (iii) surface-500-mb RH is high, or (iv) convective inhibition is weak. Errors also are relatively small when storm motion lies in the bottom-left hodograph quadrant.
\end{abstract}

\section{Introduction}

Supercell motion is an important variable for calculating certain environmental parameters when forecasting severe convection [e.g., significant tornado parameter and stormrelative helicity (SRH)] and for creating warning polygons for severe thunderstorms, flash floods, and tornadoes (e.g., Nielsen et al. 2015; Harrison and Karstens 2017). Although several forecast methods for supercell motion exist and have been evaluated (e.g., Rasmussen and Blanchard 1998, hereafter RB98; Bunkers et al. 2000, hereafter B2K; Ramsay and Doswell 2005), little is known about the error statistics of individual methods. For example, does a given method work better for straight or curved hodographs, or for fast or slow storm motions? This error information could indicate when to be cautious about using a given supercell motion forecast, and thus it potentially could help a forecaster better anticipate how a supercell will move in these situations.

This study attempts to answer the following question: Under what conditions do the largest and smallest right-

Corresponding author: Dr. Matthew J. Bunkers, matthew. bunkers@noaa.gov moving supercell motion forecast errors occur? To this end, a large observed supercell dataset is partitioned based on several environmental and storm characteristics, and then two Galilean-invariant supercell motion forecast methods are applied to these partitions. These methods (discussed in the next section) were chosen because their mean absolute errors (MAEs) are at least $0.5-1.1 \mathrm{~m} \mathrm{~s}^{-1}$ smaller than the MAEs for the other methods examined by Ramsay and Doswell (2005).

It is shown that there are indeed situations where the B2K method (as well as a modified version of the RB98 method) performs notably better or worse than average depending on the environment and storm attributes. Moreover, as reported in previous studies, the $\mathrm{B} 2 \mathrm{~K}$ method does result in the minimum MAE for predicting supercell motion. These strengths and weaknesses of predicting supercell motion-discussed below-are important to keep in mind when properly applying the B2K method.

\section{Data and methods}

a. Data

The 615-case observed supercell dataset of Bunkers et al. (2014) was used for the present study. Their 
TABLE 1. Environmental and storm-related variables for the 573-case supercell dataset. The 10th and 90th percentiles of the variables were used for partitioning the dataset into groupings of 57 cases for each of the low and high values, respectively. All ML calculations utilized the lowest $1 \mathrm{~km}(3280 \mathrm{ft})$ of the observed sounding. The equation for $\mathrm{STP}_{\text {eff }}$ was modified slightly in order to compute the $10 \mathrm{th}$ percentile value (otherwise it would not have been unique). Specifically, the upper MLLCL constraint was changed from 2000 to $2500 \mathrm{~m}$, and the lower MLCIN constraint was changed from -200 to $-225 \mathrm{~J} \mathrm{~kg}^{-1}$; this did not change the 90th percentile value.

\begin{tabular}{|c|c|c|}
\hline Variable & 10th percentile & 90th percentile \\
\hline Surface-700-mb relative humidity $\left(\mathrm{RH}_{\mathrm{Sfc}-7}\right)$ & $39.3 \%$ & $82.7 \%$ \\
\hline Surface- $500-\mathrm{mb}$ relative humidity $\left(\mathrm{RH}_{\mathrm{Sfc}-5}\right)$ & $41.1 \%$ & $76.8 \%$ \\
\hline $700-500-\mathrm{mb}$ relative humidity $\left(\mathrm{RH}_{7-5}\right)$ & $27.7 \%$ & $78.4 \%$ \\
\hline $700-\mathrm{mb}$ temp $\left(T_{7}\right)$ & $3.9^{\circ} \mathrm{C}$ & $12.8^{\circ} \mathrm{C}$ \\
\hline Bulk wind difference $\left(0-6 \mathrm{~km}\right.$, Bulk $\left._{0-6}\right)$ & $15.5 \mathrm{~m} \mathrm{~s}^{-1}(30.2 \mathrm{kt})$ & $32.1 \mathrm{~m} \mathrm{~s}^{-1}(62.3 \mathrm{kt})$ \\
\hline Bulk wind difference $\left(0-12 \mathrm{~km}\right.$, Bulk $\left._{0-12}\right)$ & $20.2 \mathrm{~m} \mathrm{~s}^{-1}(39.3 \mathrm{kt})$ & $48.3 \mathrm{~m} \mathrm{~s}^{-1}(93.9 \mathrm{kt})$ \\
\hline Height-based mean wind magnitude $\left(0-6 \mathrm{~km}, \mathrm{MW}_{0-6}\right)$ & $6.3 \mathrm{~m} \mathrm{~s}^{-1}(12.2 \mathrm{kt})$ & $20.8 \mathrm{~m} \mathrm{~s}^{-1}(40.4 \mathrm{kt})$ \\
\hline Height-based mean wind magnitude $\left(0-8 \mathrm{~km}, \mathrm{MW}_{0-8}\right)$ & $8.8 \mathrm{~m} \mathrm{~s}^{-1}(17.1 \mathrm{kt})$ & $23.3 \mathrm{~m} \mathrm{~s}^{-1}(45.3 \mathrm{kt})$ \\
\hline MLCAPE & $184.8 \mathrm{~J} \mathrm{~kg}^{-1}$ & $3191.1 \mathrm{~J} \mathrm{~kg}^{-1}$ \\
\hline MLCIN & $-165.0 \mathrm{~J} \mathrm{~kg}^{-1}$ & $-2.6 \mathrm{~J} \mathrm{~kg}^{-1}$ \\
\hline MLLCL & $753.7 \mathrm{~m}(2472.1 \mathrm{ft})$ & $2448.9 \mathrm{~m}(8032.4 \mathrm{ft})$ \\
\hline MLLFC & $1114.1 \mathrm{~m}(3654.2 \mathrm{ft})$ & $3656.1 \mathrm{~m}(11992.0 \mathrm{ft})$ \\
\hline Observed effective significant tornado parameter $\left(\mathrm{STP}_{\mathrm{eff}}\right)$ & -0.008 & 3.07 \\
\hline Observed storm-relative helicity $\left(0-3 \mathrm{~km} ; \mathrm{SRH}_{0-3}\right)$ & $57.6 \mathrm{~m}^{2} \mathrm{~s}^{-2}$ & $368.0 \mathrm{~m}^{2} \mathrm{~s}^{-2}$ \\
\hline Observed storm-relative wind $\left(4-5 \mathrm{~km} ; \mathrm{SRW}_{4-5}\right)$ & $6.0 \mathrm{~m} \mathrm{~s}^{-1}(11.7 \mathrm{kt})$ & $14.7 \mathrm{~m} \mathrm{~s}^{-1}(28.6 \mathrm{kt})$ \\
\hline Observed storm-relative wind $\left(9-10 \mathrm{~km}\right.$; $\left.\mathrm{SRW}_{9-10}\right)$ & $10.6 \mathrm{~m} \mathrm{~s}^{-1}(20.6 \mathrm{kt})$ & $31.7 \mathrm{~m} \mathrm{~s}^{-1}(61.6 \mathrm{kt})$ \\
\hline Observed supercell motion (SCM) & $5.7 \mathrm{~m} \mathrm{~s}^{-1}(11.1 \mathrm{kt})$ & $19.0 \mathrm{~m} \mathrm{~s}^{-1}(36.9 \mathrm{kt})$ \\
\hline
\end{tabular}

unmodified observed soundings were obtained from within the inflow region of the supercell, and the supercell motion was calculated when the storm was $\pm 3 \mathrm{~h}$ and within $185 \mathrm{~km}(100 \mathrm{n} \mathrm{mi})$ of the sounding release (using the most deviant/steady 1-h motion). These criteria are looser than those proposed by Potvin et al. (2010) (e.g., $40-80 \mathrm{~km}$ and $\pm 2 \mathrm{~h}$ or $0-40 \mathrm{~km}$ and $1-2 \mathrm{~h}$ ) in their study of significant tornado environments. The effects of longer space and time constraints in the present study should be minimal as supercell motion calculations are not overly sensitive to small perturbations in the hodograph. Only 573 cases have concurrent kinematic and thermodynamic information through 0-12 km AGL, whereas all 615 cases have kinematic information in this layer (the 573 cases with complete data are used herein). The reader is referred to Bunkers et al. (2014) for additional information on this dataset.

\section{b. Variables and partitioning}

The 573-case dataset was partitioned based on small versus large values of the environmental and storm-related variables given in Table 1 . The goal of testing these variables was to identify conditions where the forecast motions do either well or poorly. Here, small (large) refers to the lowest (highest) $10 \%$ of the distribution, which rounds to 57 cases in each of the low and high categories. This number of cases is sufficiently large to provide an approximate Gaussian distribution. The lower and upper deciles were selected to focus on the extremes as these were expected to provide the best- or worst-case scenarios in terms of supercell motion forecast errors.
Regarding the environmental variables, the mixedlayer (ML; lowest $1 \mathrm{~km}$ of the sounding in this study) convective available potential energy (MLCAPE), ML lifted condensation level (MLLCL), ML level of free convection (MLLFC), and relative humidity $(\mathrm{RH})$ for three layers were examined based on observations from Craven et al. (2002) and the modeling studies of Kirkpatrick et al. (2007) and Grant and Van den Heever (2014). Two shear layers and two mean wind (MW) layers (see Table 1) also were evaluated given their importance to supercell formation and motion, respectively. Furthermore, ML convective inhibition (MLCIN) was examined as it can modulate the amount of surface-based air entering the updraft (e.g., Nowotarski et al. 2011), as was the $700-\mathrm{mb}(1 \mathrm{mb}=1 \mathrm{hPa})$ temperature because of its relationship to MLCIN (e.g., Bunkers et al. 2010).

For the storm-related variables, two storm-relative wind layers (see Table 1) were chosen based on the work of Brown (1993) and Rasmussen and Straka (1998), and the effective significant tornado parameter $\left(\mathrm{STP}_{\mathrm{eff}}\right.$, which depends on storm motion) was chosen to reflect the current operational version used by the Storm Prediction Center (Thompson et al. 2012). Supercell motion was a natural consideration, and the $0-3-\mathrm{km}$ SRH was examined because of its dependence on storm motion. Other storm characteristics (not listed in Table 1) included storm motion relative to hodograph quadrant and the tornado damage scale.

\section{c. Supercell motion methods and their evaluation}

The shear-based methods of RB98 and B2K were employed to examine the supercell motion errors as a 
TABLE 2. Number of cases with the observed supercell motion in each of the four quadrants of the hodograph, along with the MAE $\left(\mathrm{m} \mathrm{s}^{-1}\right)$, RMSE $\left(\mathrm{m} \mathrm{s}^{-1}\right)$, and bias $\left({ }^{\circ}, \mathrm{m} \mathrm{s}^{-1}\right)$ for the B2K and RB98mod methods for each of the four quadrants. The bias direction $\left({ }^{\circ}\right)$ is with respect to the observed storm motion (e.g., $270^{\circ}$ means the forecast is biased west of the observation). The MAE for the bottom-left quadrant is significantly different (5\% level) from the other quadrants for both methods.

\begin{tabular}{|c|c|c|c|c|c|c|c|}
\hline \multirow[b]{2}{*}{ Quadrant of storm motion } & \multirow[b]{2}{*}{ No. of cases } & \multicolumn{3}{|c|}{ B2K results } & \multicolumn{3}{|c|}{ RB98mod results } \\
\hline & & MAE & RMSE & Bias & MAE & RMSE & Bias \\
\hline All & $573(100 \%)$ & 3.2 & 3.7 & $324^{\circ} / 0.48$ & 3.8 & 4.3 & $251^{\circ} / 0.72$ \\
\hline Top left & $0(0 \%)$ & - & - & - & - & - & - \\
\hline Top right & $243(42.4 \%)$ & 3.2 & 3.8 & $348^{\circ} / 0.37$ & 4.0 & 4.6 & $214^{\circ} / 0.72$ \\
\hline Bottom left & $22(3.8 \%)$ & 2.3 & 2.7 & $40^{\circ} / 0.80$ & 2.8 & 3.1 & $276^{\circ} / 0.35$ \\
\hline Bottom right & $308(53.8 \%)$ & 3.3 & 3.7 & $308^{\circ} / 0.64$ & 3.7 & 4.2 & $271^{\circ} / 0.92$ \\
\hline
\end{tabular}

function of the above variables. Both of these methods perform reasonably well for the range of observed hodographs, even though they also perform poorly at times (e.g., Ramsay and Doswell 2005) - hence the reason for this study.

Ramsay and Doswell (2005) found that "the combination of the BL-5 km bulk shear layer and a deviation vector of $7.5 \mathrm{~m} \mathrm{~s}^{-1}$ resulted in the least error dispersion, and also shared the minimum MDVE" for the RB98 method (BL = lowest $500 \mathrm{~m}$ and $\mathrm{MDVE}=$ minimum median vector error). This modification and the original RB98 method were tested with the present dataset, and it was found that the modified RB98 method reduces the MAE by $0.72 \mathrm{~m} \mathrm{~s}^{-1}$ and the root-mean-squared error (RMSE) by $0.76 \mathrm{~m} \mathrm{~s}^{-1}$. Thus, the modified RB98 method (RB98mod) specified by Ramsay and Doswell (2005) was used herein and is given as

$$
\mathbf{V}_{\mathrm{RM}}=\mathbf{V}_{\mathrm{BL}}+0.6 \frac{\partial \mathbf{V}}{\partial z}+D\left(\frac{\frac{\partial \mathbf{V}}{\partial z} \times \hat{\boldsymbol{k}}}{\left|\frac{\partial \mathbf{V}}{\partial z}\right|}\right),
$$

where $\mathbf{V}_{\mathrm{BL}}$ is the $0.0-0.5-\mathrm{km}$ height-based mean wind, $\partial \mathbf{V} / \partial z$ is the $0-0.5$ - to $5.0-\mathrm{km}$ vertical wind shear vector, and $D$ is the deviation $\left(7.5 \mathrm{~m} \mathrm{~s}^{-1}\right)$ from the shear vector (perpendicular and to the right). The sum of the first two terms on the right-hand side of Eq. (1) essentially represents the mean wind.

Ramsay and Doswell (2005) also concluded that a $0-8-\mathrm{km}$ mean wind is optimal for the $\mathrm{B} 2 \mathrm{~K}$ method, but more recent research supports the 0-6-km layer (Thompson et al. 2007; Bunkers et al. 2014). Indeed, calculations with the present dataset show an increase in the MAE (RMSE) of $0.87 \mathrm{~m} \mathrm{~s}^{-1}\left(0.93 \mathrm{~m} \mathrm{~s}^{-1}\right)$ when using the $0-8-\mathrm{km}$ mean wind (vs $0-6 \mathrm{~km}$ ). Moreover, although Bunkers et al. (2014) proposed a modification to the mean wind, they also stated that "the $0-6-\mathrm{km}$ height-based mean wind is reasonably robust, with little gained by more complicated methods." Therefore, the original B2K method was used for the present study and is given as

$$
\mathbf{V}_{\mathrm{RM}}=\mathbf{V}_{\text {mean }}+D\left(\frac{\frac{\partial \mathbf{V}}{\partial z} \times \hat{\boldsymbol{k}}}{\left|\frac{\partial \mathbf{V}}{\partial z}\right|}\right),
$$

where $\mathbf{V}_{\text {mean }}$ is the 0-6-km height-based mean wind, $\partial \mathbf{V} / \partial \mathbf{z}$ is the $0-0.5-$ to $5.5-6.0-\mathrm{km}$ vertical wind shear vector, and $D$ is the deviation $\left(7.5 \mathrm{~m} \mathrm{~s}^{-1}\right)$ from the mean wind (perpendicular and to the right of the shear vector).

Finally, the MAE and RMSE (which is sensitive to large errors) were used to evaluate the two supercell motion methods. The bias also was calculated, with the output given as the azimuth/range from the observed storm motion (e.g., a bias of $270^{\circ} / 2$ indicates the forecast is west of the observed motion by $2 \mathrm{~m} \mathrm{~s}^{-1}$ ). The bias (computed by averaging the errors) typically is much smaller than the MAE/RMSE because the observed storm motions are scattered fairly symmetrically around the predicted motion. To aid in comparison of the variables, hodographs were composited using the methods of Bunkers et al. (2006, see the caption to their Fig. 5), and soundings were composited using the Universal Rawinsonde Observation (raob) program (http://www.raob.com/).

\section{Results and discussion}

\section{a. Errors by hodograph quadrant}

Initially, the cases were partitioned based on where the observed supercell motion fell within the four hodograph quadrants. Per B2K, the observed motion was calculated manually by tracking the storm centroid over about an hour when the storm was most intense and isolated. Although the Galilean-invariant forecast methods should perform the same regardless of hodograph quadrant, the synoptic-to-mesoscale influences can be different in the various quadrants (e.g., Johns 1984; Banacos and Bluestein 2004), and these influences might affect the predictions.

The most common scenario is for storm motion to be in the bottom-right quadrant $(53.8 \%$, Table 2$)$, with the next 

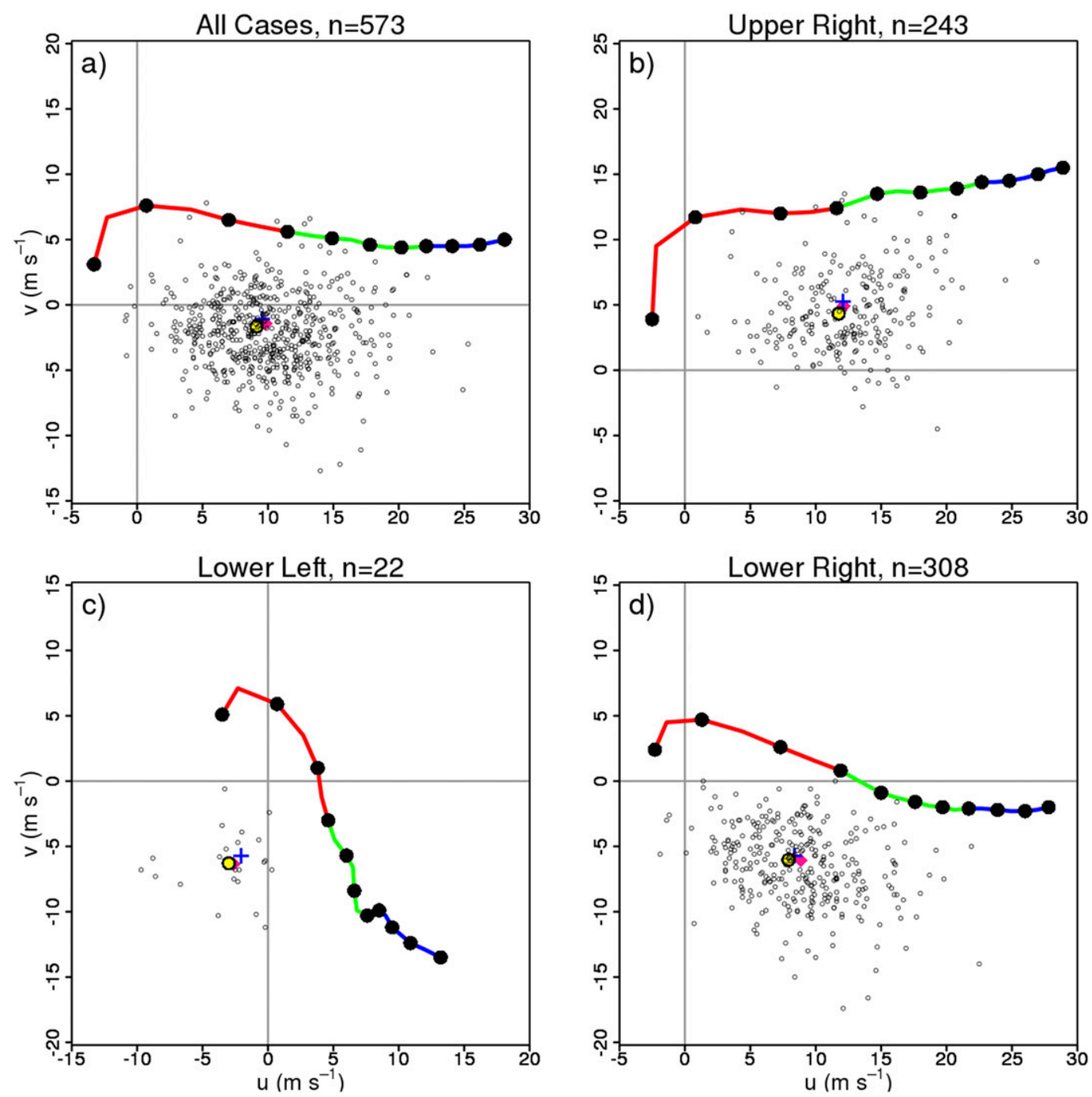

FIG. 1. Composite 0-10-km hodographs for (a) all 573 cases as well as for those with observed storm motions in the (b) top-right, (c) bottom-left, and (d) bottom-right quadrants of the hodograph; none occurred with storm motions in the top-left quadrant. Data are plotted every $0.5 \mathrm{~km}$ with filled black circles every $1 \mathrm{~km}$; red, green, and blue colors highlight the 0-3-, 3-7-, and 7-10-km layers for ease of comparison. The composite observed storm motion is given by a pink diamond, the B2K forecast by a blue plus sign, and the RB98mod forecast by a yellow circle with black outline. All individual storm motions are plotted as small open circles (after an adjustment process). The hodographs and storm motions were adjusted by adding back the original composite mean wind $\left(\mathrm{MW}_{0-6}\right)$ and aligning with the original composite $0.0-0.5-$ to $5.5-6.0-\mathrm{km}$ shear vector (see Bunkers et al. 2006 for details). Note that the difference between the composite observed and forecast motions represents the bias on these plots, and not the MAE (which is listed in Table 2).

most common quadrant being the top right (42.4\%). No cases were observed in the present dataset with the supercell motion in the top-left quadrant (Table 2), although rare cases like this have occurred (e.g., Finch and Bikos 2010).

Supercell motion forecast errors are similar among the top-right and bottom-right quadrants, and the bias for the forecast motion is $<1 \mathrm{~m} \mathrm{~s}^{-1}$ for all quadrants for both methods (Table 2). However, the bottom-left quadrant has the smallest errors by $\sim 1 \mathrm{~m} \mathrm{~s}^{-1}$, although this involves only $3.8 \%$ (or 22 ) of the cases. Despite the small sample size for the bottom-left quadrant, tests for differences in MAEs between the bottom-left quadrant versus those of both the top-right and bottom-right quadrants are significant at the 5\% level [using a twotailed Wilcoxon-Mann-Whitney (or rank sum) test (Wilks 2011)]. These smaller errors for "atypical" hodographs are consistent with the results of B2K and Ramsay and Doswell (2005).

The hodograph shapes are similar among the various quadrants (Fig. 1), though the top-right quadrant composite 
TABLE 3. As in Table 2, but for nontornadic, weakly tornadic (EF0 and EF1), significantly tornadic ( $\geq \mathrm{EF} 2$ ), and violently tornadic ( $\geq E F 4)$ cases. The number of cases for the first three rows is 573 . Note that the Fujita (F) scale transitioned to the enhanced Fujita (EF) scale on 1 Feb 2007 (Doswell et al. 2009), but EF is used generically herein.

\begin{tabular}{|c|c|c|c|c|c|c|c|}
\hline \multirow[b]{2}{*}{ Tornado partition } & \multirow[b]{2}{*}{ No. of cases } & \multicolumn{3}{|c|}{ B2K results } & \multicolumn{3}{|c|}{ RB98mod results } \\
\hline & & MAE & RMSE & Bias & MAE & RMSE & Bias \\
\hline Nontornadic & $371(64.7 \%)$ & 3.1 & 3.6 & $288^{\circ} / 0.50$ & 3.7 & 4.3 & $246 \% / 0.84$ \\
\hline Weak & $127(22.2 \%)$ & 3.3 & 3.8 & $337^{\circ} / 0.82$ & 3.8 & 4.5 & $259^{\circ} / 0.54$ \\
\hline Significant & $75(13.1 \%)$ & 3.5 & 4.1 & $39^{\circ} / 1.17$ & 3.9 & 4.6 & $273 \% / 0.45$ \\
\hline Violent & $17(3.0 \%)$ & 3.5 & 4.2 & $60^{\circ} / 1.30$ & 3.9 & 4.7 & $61^{\circ} / 0.18$ \\
\hline
\end{tabular}

hodograph has the largest $\mathrm{SRH}_{0-3}$ at $215 \mathrm{~m}^{2} \mathrm{~s}^{-2}$ (vs $145 \mathrm{~m}^{2} \mathrm{~s}^{-2}$ for the bottom-left hodograph)—owing to differences mostly in the lowest $1 \mathrm{~km}$. The composite hodographs also exhibit orientations that differ substantially from top right through bottom right and bottom left (Fig. 1). In particular, the hodograph with storm motions in the top-right quadrant has southwest flow aloft, whereas the hodograph with storm motions in the bottom-left quadrant has northwest flow aloft (e.g., Johns 1984). The composite hodograph for all cases (Fig. 1a) is similar to the composite hodographs of Markowski et al. (2003; see their Fig. 12).

\section{b. Errors by tornado damage scale}

Storm motion errors vary between the B2K and RB98mod methods with respect to the Fujita/enhanced Fujita damage scale (Doswell et al. 2009). Specifically, the MAE (RMSE) increases by $0.4 \mathrm{~m} \mathrm{~s}^{-1}\left(0.6 \mathrm{~m} \mathrm{~s}^{-1}\right)$ from nontornadic to violently tornadic storms for the B2K method; however, the increases are smaller $(0.2$ and $0.4 \mathrm{~m} \mathrm{~s}^{-1}$, respectively) for the RB98mod method (Table 3). Nevertheless, the differences in MAEs between the nontornadic and violently tornadic cases, for both methods, are not statistically significant (5\% level).

In addition to the errors, the bias increases steadily for the $\mathrm{B} 2 \mathrm{~K}$ method, going from $0.50 \mathrm{~m} \mathrm{~s}^{-1}$ for nontornadic storms to $1.30 \mathrm{~m} \mathrm{~s}^{-1}$ for violently tornadic storms (Table 3). Conversely, the bias is smaller for the RB98mod method (cf. B2K) for all tornadic partitions, dropping to only $0.18 \mathrm{~m} \mathrm{~s}^{-1}$ for the violently tornadic storms. The composite hodographs for the four tornado partitions illustrate this point with the observed (pink diamond) and RB98mod (yellow circle) motions nearly coincident in all of the plots (Fig. 2). Thus, although the bias for all 573 cases is similar between the two methods (Table 2, Fig. 1a), and the B2K method has smaller MAEs for the tornadic cases (Table 3), the RB98mod method clearly has a smaller bias for the tornadic cases.

This tendency for farther rightward deviation of tornadic versus nontornadic supercells was noted by Parker (2014; see his Fig. 12), and in addition, his tornadic supercells moved faster than the nontornadic supercells (this is evident in Fig. 2, too). This stronger rightward deviation of tornadic supercells also is implicit in the composite hodographs of Markowski et al. (2003; see their Fig. 12), as well as in the results from Thompson et al. (2003; see their Fig. 13) where the observed 4-6-km storm-relative wind is stronger than predicted for the significantly tornadic supercells. These observational findings are consistent with the early modeling work of Weisman and Klemp (1984; see their Fig. 8), and partly can be attributed to enhanced updraft-shear interactions whereby stronger and more pronounced low-level clockwise-turning shear vectors promote stronger offhodograph deviation (e.g., Davies-Jones 2002).

Information on these observed storm motion differences from predicted values might be useful operationally. For example, the National Weather Service (NWS 2011) service assessment of the 22 May 2011 Joplin, Missouri, tornado noted that the primary radar operator observed the storm motion to be more "deviant" than originally anticipated (by the B2K method). The forecaster used this knowledge, in combination with other data, to issue the tornado warning for Joplin earlier than otherwise supposedly would have been the case. However, this is just one case/example, and thus further research is needed to determine the potential applicability of this result.

\section{c. Errors for environmental and storm-related variables}

\section{1) LARGEST ERRORS}

To provide a relative comparison for the $\mathrm{B} 2 \mathrm{~K}$ and RB98mod methods, the average of the MAEs for each method was compared to the standard deviation of the MAEs across the four categories (i.e., lower $10 \%$ B2K, upper $10 \%$ B2K, lower 10\% RB98mod, and upper $10 \%$ RB98mod). Given the small sample size (17 variables per column; Table 1), values of at least one standard deviation from the mean are highlighted in Table 4 because two standard deviations would have yielded too few results. Statistical significance at the 5\% level also is highlighted with an asterisk, where appropriate, for 

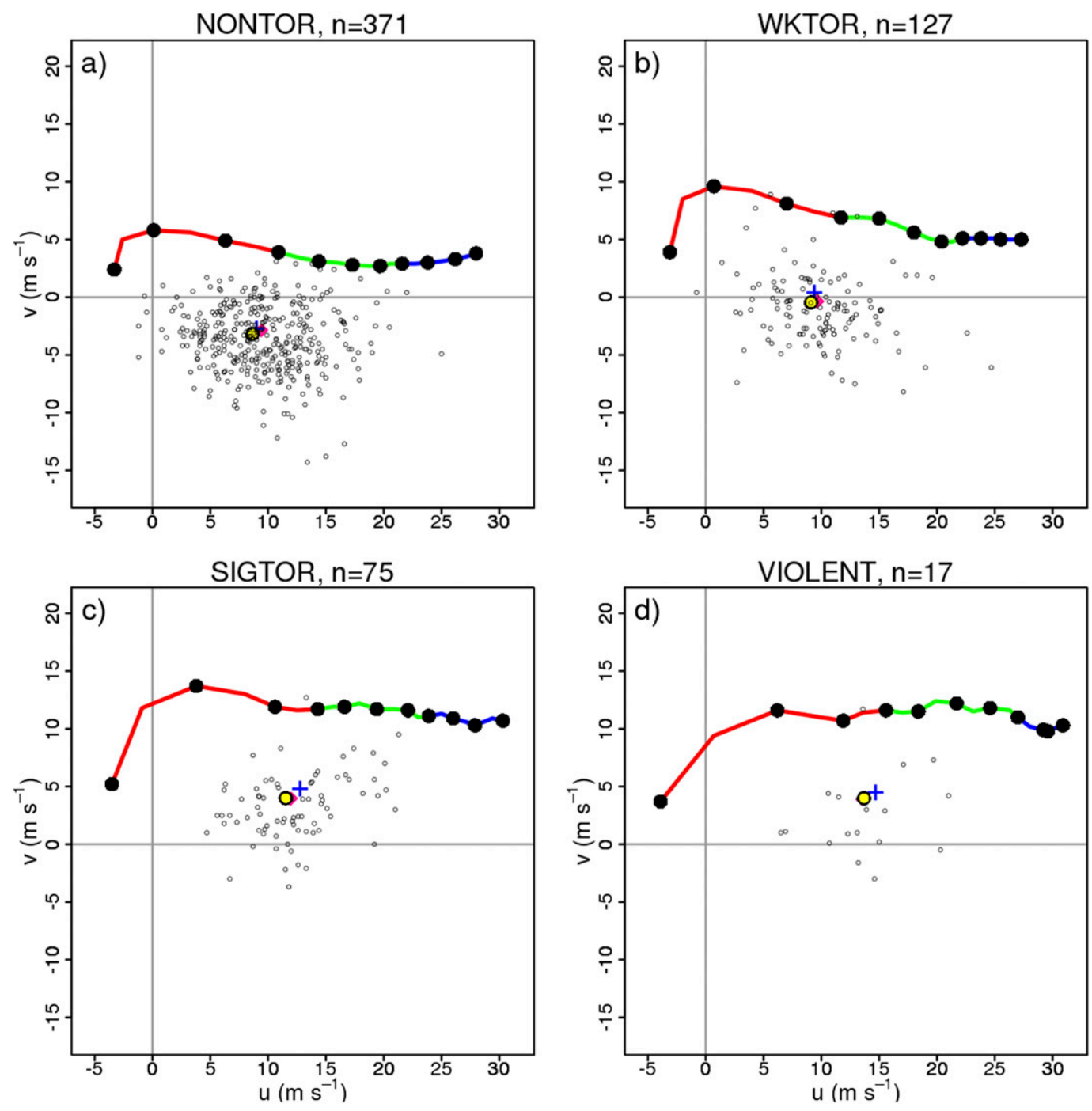

FIG. 2. As in Fig. 2, but for (a) nontornadic (NONTOR), (b) weakly tornadic (WKTOR), (c) significantly tornadic (SIGTOR), and (d) violently tornadic (VIOLENT) cases. For reference, $\mathrm{SRH}_{0-3}$ values for the hodographs in (a)-(d) are $147,188,249$, and $222 \mathrm{~m}^{2} \mathrm{~s}^{-2}$, respectively.

these values (i.e., by comparing the MAE for that variable to the average MAE of its associated column; the latter of which is at the top of Table 4).

The largest forecast supercell motion errors are evident when the observed 4-5 km AGL storm-relative wind $\left(\mathrm{SRW}_{4-5}\right)$ is anomalously weak or strong (Table 4; MAEs $=3.9-5.5 \mathrm{~m} \mathrm{~s}^{-1}$ and RMSEs $\left.=4.3-5.9 \mathrm{~m} \mathrm{~s}^{-1}\right)$. Errors this large $\left(>4.0 \mathrm{~m} \mathrm{~s}^{-1}\right)$ can have substantial impacts on NWS warning polygons such that the storm starts moving outside of the polygon after $15-30 \mathrm{~min}$ (e.g., $>7-\mathrm{km}$ error after $30 \mathrm{~min}$ ). These results are statistically significant at the $5 \%$ level. Moreover, the largest biases of all cases occur here with values of 2.9$4.5 \mathrm{~m} \mathrm{~s}^{-1}$, which can adversely affect the timing of threats within NWS warnings (e.g., $>5 \mathrm{~km}$ too soon or late in $30 \mathrm{~min}$ ). This is somewhat of an expected result because $\mathrm{SRW}_{4-5}$ and storm motion are strongly related. For example, if the storm motion deviates substantially from the hodograph, this will increase the storm-relative wind. To examine this further, $\mathrm{SRW}_{4-5}$ was calculated using the forecast motion instead of the observed motion. Partitioning $\mathrm{SRW}_{4-5}$ based on forecast motions results in smaller supercell motion errors by 0.8 $2.0 \mathrm{~m} \mathrm{~s}^{-1}$ for the lower and upper $10 \%$ of the cases, relative to what was found when using the observed $\mathrm{SRW}_{4-5}$ (Fig. 3; cf. the MAEs for the hodographs in the top row to those in the bottom two rows).

This presents a quandary to the forecaster because it is unclear when to trust the forecast supercell motion in these cases. Upon examination of the hodographs for 
TABLE 4. MAE $\left(\mathrm{m} \mathrm{s}^{-1}\right)$, RMSE $\left(\mathrm{m} \mathrm{s}^{-1}\right)$, and bias $\left({ }^{\circ}, \mathrm{m} \mathrm{s}^{-1}\right)$ for the B2K and RB98mod methods for the 57 cases in the lowest $10 \%$ and highest $10 \%$ for each of the 17 respective variables. Values highlighted in italics (boldface) indicate MAEs that are at least one standard deviation less (greater) than the mean of the MAEs for that particular column (top row). Column-specific statistical significance of the MAEs at the $5 \%$ level is indicated with an asterisk.

\begin{tabular}{|c|c|c|c|c|c|c|c|c|c|c|c|c|}
\hline \multirow[b]{2}{*}{ Variable } & \multicolumn{3}{|c|}{ Lowest $10 \% \mathrm{~B} 2 \mathrm{~K}$ results } & \multicolumn{3}{|c|}{$\begin{array}{l}\text { Lowest } 10 \% \\
\text { RB98mod results }\end{array}$} & \multicolumn{3}{|c|}{ Upper $10 \%$ B2K results } & \multicolumn{3}{|c|}{$\begin{array}{c}\text { Upper } 10 \% \\
\text { RB98mod results }\end{array}$} \\
\hline & MAE & RMSE & Bias & MAE & RMSE & Bias & MAE & RMSE & Bias & MAE & RMSE & Bias \\
\hline All 17 variables & 3.3 & 3.8 & $288^{\circ} / 0.61$ & 3.9 & 4.5 & $248^{\circ} / 1.13$ & 3.4 & 4.0 & $4 \% .82$ & 4.1 & 4.7 & $258^{\circ} / 0.40$ \\
\hline $\mathrm{RH}_{\mathrm{Sfc}-7}$ & 3.5 & 4.0 & $285^{\circ} / 1.07$ & 3.8 & 4.4 & $273^{\circ} / 0.87$ & 3.2 & 3.7 & $60^{\circ} / 1.14$ & 3.7 & 4.3 & $156^{\circ} / 0.60$ \\
\hline $\mathrm{RH}_{\mathrm{Sfc}-5}$ & $3.6^{*}$ & 4.1 & $292^{\circ} / 1.16$ & 3.7 & 4.2 & $280^{\circ} / 1.18$ & $2.9^{*}$ & 3.4 & $81^{\circ} / 0.53$ & 3.6 & 4.3 & $158^{\circ} / 0.70$ \\
\hline $\mathrm{RH}_{7-5}$ & 3.5 & 4.0 & $348^{\circ} / 1.13$ & 4.2 & 5.0 & $288^{\circ} / 1.16$ & 3.1 & 3.4 & $285^{\circ} / 0.85$ & 4.0 & 4.6 & $229^{\circ} / 1.24$ \\
\hline$T_{7}$ & 3.3 & 3.7 & $71^{\circ} / 0.59$ & 4.0 & 4.5 & $150^{\circ} / 0.25$ & 3.5 & 4.1 & $280^{\circ} / 1.31$ & 3.9 & 4.6 & $250^{\circ} / 1.52$ \\
\hline Bulk $_{0-6}$ & 3.1 & 3.6 & $301^{\circ} / 0.43$ & 3.8 & 4.4 & $254^{\circ} / 1.15$ & 3.5 & 4.0 & $14^{\circ} / 1.11$ & 4.3 & 4.8 & $21 \% 0.37$ \\
\hline Bulk $_{0-12}$ & 3.2 & 3.7 & $276^{\circ} / 0.59$ & 4.1 & 4.6 & $244^{\circ} / 1.53$ & 3.0 & 3.4 & $336^{\circ} / 0.95$ & 4.0 & 4.7 & $305^{\circ} / 0.83$ \\
\hline $\mathrm{MW}_{0-6}$ & 3.0 & 3.4 & $282^{\circ} / 1.10$ & 3.5 & 4.1 & $251^{\circ} / 1.58$ & 3.7 & 4.2 & $51^{\circ} / 1.32$ & 4.2 & 4.8 & $172^{\circ} / 0.51$ \\
\hline $\mathrm{MW}_{0-8}$ & $2.8^{*}$ & 3.1 & $287^{\circ} / 1.01$ & 3.5 & 4.1 & $250^{\circ} / 1.41$ & 3.3 & 3.8 & $55^{\circ} / 1.55$ & 3.7 & 4.3 & $84^{\circ} / 0.31$ \\
\hline MLCAPE & 3.1 & 3.6 & $281^{\circ} / 0.70$ & 3.8 & 4.3 & $260^{\circ} / 1.24$ & 3.4 & 4.1 & $314^{\circ} / 1.00$ & 4.4 & 5.1 & $265^{\circ} / 1.67$ \\
\hline MLCIN & 3.7 & 4.2 & $315^{\circ} / 1.31$ & 4.3 & 4.9 & $271^{\circ} / 1.92$ & 3.0 & 3.7 & $22 \% 0.98$ & $3.6^{*}$ & 4.2 & $172^{\circ} / 0.20$ \\
\hline MLLCL & 3.2 & 3.9 & $39^{\circ} / 0.88$ & 4.0 & 4.9 & $169^{\circ} / 0.42$ & 3.3 & 3.7 & $282^{\circ} / 1.05$ & 3.6 & 4.1 & $260^{\circ} / 0.79$ \\
\hline MLLFC & 3.2 & 3.7 & $59^{\circ} / 0.72$ & 3.7 & 4.2 & $166^{\circ} / 0.65$ & 3.5 & 4.1 & $282 \% 0.33$ & 4.4 & 4.9 & $224^{\circ} / 1.12$ \\
\hline $\mathrm{STP}_{\text {eff }}$ & 3.3 & 3.9 & $286^{\circ} / 1.09$ & 3.5 & 4.2 & $285^{\circ} / 1.11$ & 3.5 & 4.1 & $26^{\circ} / 1.68$ & 4.0 & 4.4 & $275^{\circ} / 0.61$ \\
\hline $\mathrm{SRH}_{0-3}$ & 3.3 & 3.7 & $190^{\circ} / 1.27$ & 3.5 & 4.0 & $193^{\circ} / 0.65$ & $4.4^{*}$ & 4.9 & $343^{\circ} / 2.53$ & $4.6^{*}$ & 5.3 & $269^{\circ} / 1.79$ \\
\hline $\mathrm{SRW}_{4-5}$ & $3.9 *$ & 4.3 & $250^{\circ} / 2.90$ & $5.5^{*}$ & 5.9 & $240^{\circ} / 4.52$ & $4.5^{*}$ & 5.0 & $37^{\circ} / 3.10$ & $5.0^{*}$ & 5.4 & $50^{\circ} / 3.10$ \\
\hline $\mathrm{SRW}_{9-10}$ & 3.1 & 3.6 & $283^{\circ} / 1.01$ & 4.1 & 4.7 & $244^{\circ} / 2.06$ & $2.7^{*}$ & 3.1 & $28^{\circ} / 0.74$ & 3.5 & 4.1 & $33 \% 0.61$ \\
\hline SCM & 2.8 & 3.2 & $81^{\circ} / 0.35$ & $3.1^{*}$ & 3.5 & $160^{\circ} / 0.79$ & 3.8 & 4.6 & $284^{\circ} / 1.02$ & 4.6 & 5.3 & $253^{\circ} / 1.75$ \\
\hline
\end{tabular}

both the observed and forecast $\mathrm{SRW}_{4-5}$ categories, they generally are similar within the weak (lower $10 \%$ ) and within the strong (upper 10\%) $\mathrm{SRW}_{4-5}$ composites (Fig. 3; cf. the hodographs within each column). Specifically, the hodographs for the lower $10 \% \mathrm{SRW}_{4-5}$ partitions (Figs. 3a,c,e) have counterclockwise curvature from about 3 to $6 \mathrm{~km}$, although the lower $10 \% \mathrm{RB} 98 \mathrm{mod}$ $\mathrm{SRW}_{4-5}$ hodograph (Fig. 3e) has a relatively muted curvature.

The hodographs for the upper $10 \%$ of the observed and forecast $\mathrm{SRW}_{4-5}$ cases (Figs. 3b,d,f) are even more similar to each other than for those within the lower $10 \%$ of cases. All three of them feature relatively strong shear from the surface to $5 \mathrm{~km}$ that is coupled with much weaker shear in the 5-10-km layer; counterclockwise curvature exists from 5 to $8 \mathrm{~km}$ for all three. Collectively, all hodographs in Fig. 3 display somewhat of an unusual counterclockwise kink in the mid- to upper levels. Apparently, this anomaly in the hodograph constitutes a challenging situation when forecasting supercell motion.

Other statistically significant (5\% level) supercell motion forecast errors occurred with hodographs associated with the upper $10 \%$ of observed $\mathrm{SRH}_{0-3}$ (Table 4; MAEs of $\left.4.4-4.6 \mathrm{~m} \mathrm{~s}^{-1}\right)$. These MAEs are $1.1 \mathrm{~m} \mathrm{~s}^{-1}$ larger than those for the lowest $10 \%$ of observed $\mathrm{SRH}_{0-3}$ (which also is statistically significant). Forecast supercell motions are biased from west through north of the observed motion by $1.8-2.5 \mathrm{~m} \mathrm{~s}^{-1}$ (Table 4, Fig. 4a). The upper $10 \% \mathrm{SRH}_{0-3}$ hodograph has strong clockwise curvature (nearly half circle) in the lowest $3 \mathrm{~km}$ AGL, and the observed $\mathrm{SRH}_{0-3}\left(455 \mathrm{~m}^{2} \mathrm{~s}^{-2}\right)$ is larger than that forecast by B2K $\left(398 \mathrm{~m}^{2} \mathrm{~s}^{-2}\right)$ while being only slightly larger than that forecast by RB $98 \bmod \left(443 \mathrm{~m}^{2} \mathrm{~s}^{-2}\right)$. The bias of the observed motion away from the concave side of the 0-3-km hodograph suggests that linear forcing of storm propagation is potentially important in these cases (e.g., Weisman and Rotunno 2000; Davies-Jones 2002). Consistent with this, the observed storm motion is biased $0.7-1.3 \mathrm{~m} \mathrm{~s}^{-1}$ closer to the hodograph for the lowest $10 \% \mathrm{SRH}_{0-3}$ partition (i.e., less off-hodograph deviation for weak low-level shear with minimal curvature; Table 4).

For the upper $10 \%$ observed supercell motion (SCM) hodograph (Fig. 4b), the forecast supercell motions are biased west (i.e., slower) of the observed motion by $1-2 \mathrm{~m} \mathrm{~s}^{-1}$, which is suggestive of either outflow dominance or relatively greater influence of the deep-layer mean wind (Ramsay and Doswell 2005; Warren et al. 2017). Indeed, this hodograph exhibits the strongest $\mathrm{MW}_{0-6}$ and $\mathrm{MW}_{0-8}$ results among all partitions. The MAEs (Table 4) are $0.6-0.8 \mathrm{~m} \mathrm{~s}^{-1}$ larger than the MAEs for all cases (Table 2), and the MAEs are $1-1.5 \mathrm{~m} \mathrm{~s}^{-1}$ larger than for the lower $10 \%$ observed SCM partition.

Finally, somewhat large supercell motion forecast errors occur with large convective inhibition (i.e., strongly negative MLCIN or the lower $10 \%$ of cases), as 

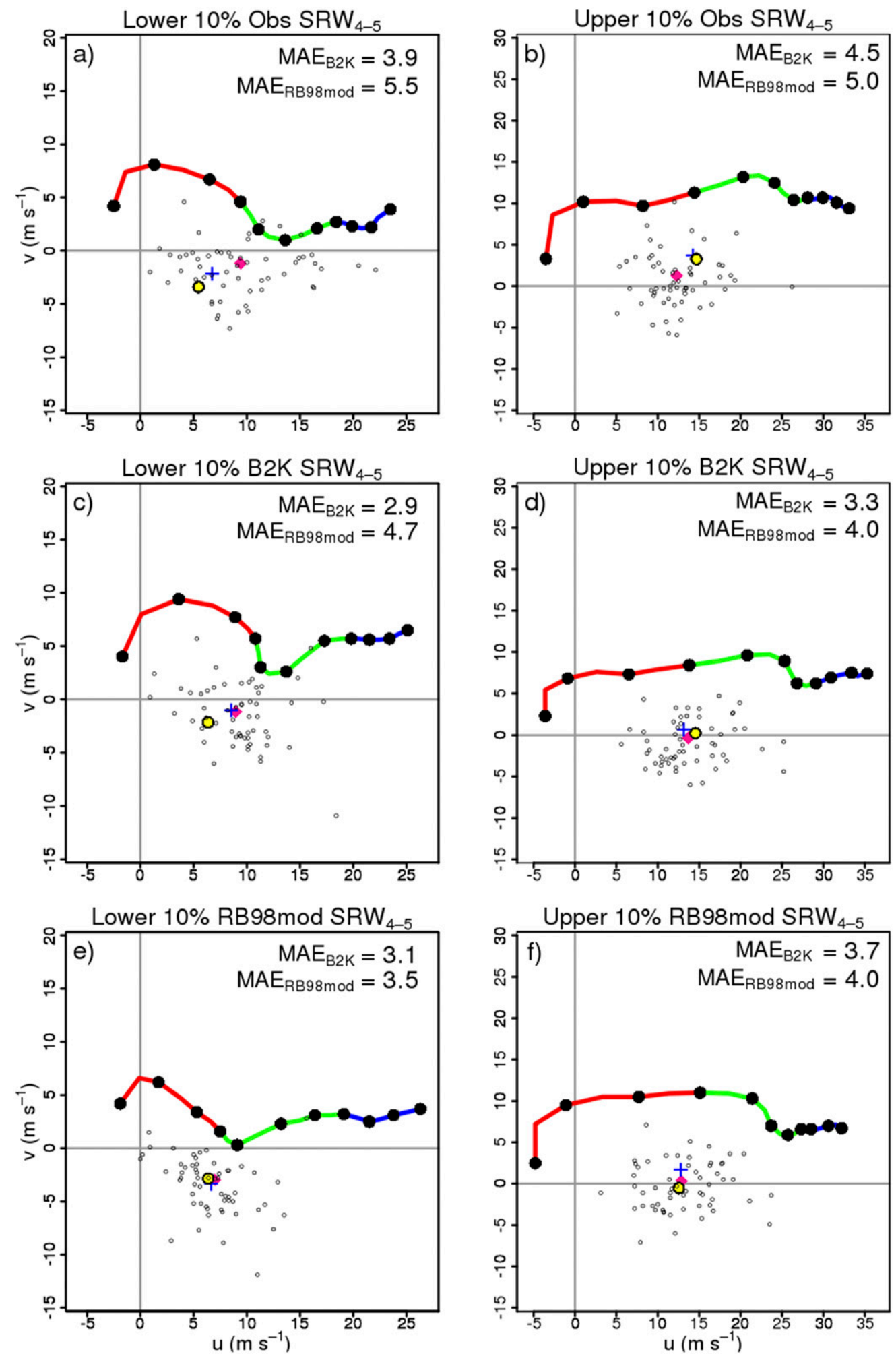

FIG. 3. As in Fig. 1, but for the 57 cases with the (a) weakest observed $\mathrm{SRW}_{4-5}$, (b) strongest observed $\mathrm{SRW}_{4-5}$, (c) weakest B2K forecast $\mathrm{SRW}_{4-5}$, (d) strongest B2K forecast $\mathrm{SRW}_{4-5}$, (e) weakest RB98mod forecast $\mathrm{SRW}_{4-5}$, and (f) strongest RB98mod forecast $\mathrm{SRW}_{4-5}$. MAEs $\left(\mathrm{m} \mathrm{s}^{-1}\right)$ also are given for each method. 

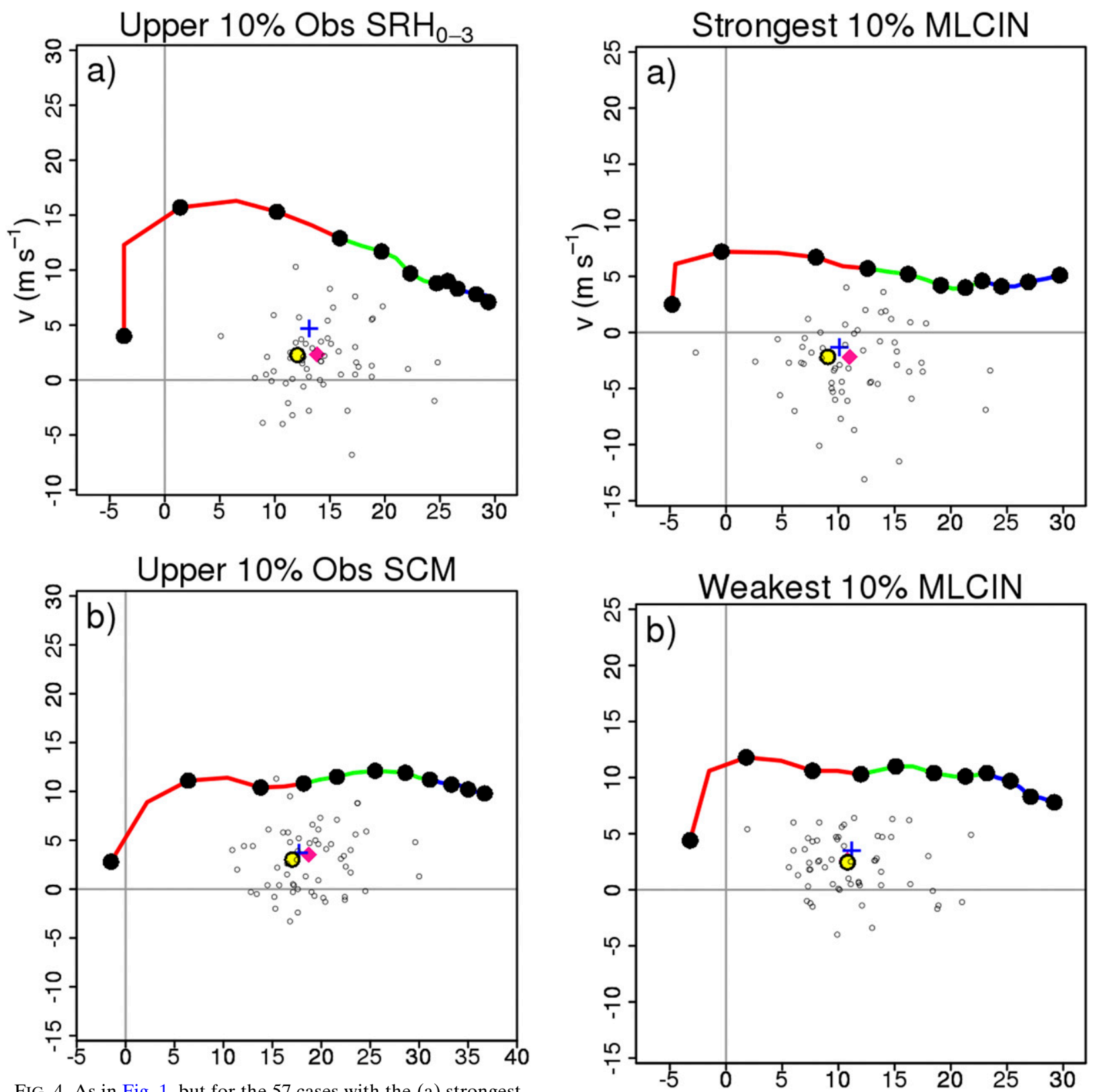

FIG. 4. As in Fig. 1, but for the 57 cases with the (a) strongest observed $\mathrm{SRH}_{0-3}$ and (b) fastest observed SCM.

FIG. 5. As in Fig. 1, but for the 57 cases with the (a) strongest (most negative) MLCIN and (b) weakest (most positive) MLCIN.

well as dry low to midlevels (i.e., low $\mathrm{RH}_{\text {Sfc-5}}$; Table 4). For both of these variables, only the B2K method has MAEs that are at least one standard deviation greater than the mean, which is statistically significant ( $5 \%$ level) for $\mathrm{RH}_{\mathrm{Sfc}-5}$. Moreover, the MAEs for the lower $10 \%$ MLCIN partition are $0.7 \mathrm{~m} \mathrm{~s}^{-1}$ larger than for the upper $10 \%$ MLCIN partition for both forecast methods, and this result is statistically significant ( $5 \%$ level).

This difference in results for strong versus weak MLCIN may be due to the cases with strong MLCIN

ingesting less surface air into the updraft than for storms with weak MLCIN (Nowotarski et al. 2011; MacIntosh and Parker 2017). Therefore, a storm with strong MLCIN is partially elevated (or at least not ingesting as much surface-based air as otherwise would be the case), exhibiting a bias of a faster/eastward observed motion (by $1-2 \mathrm{~m} \mathrm{~s}^{-1}$; Table 4). The composite hodograph for the strongest $10 \%$ MLCIN cases (Fig. 5a) has a slightly stronger easterly component to the surface wind and a weaker southerly component throughout the hodograph 

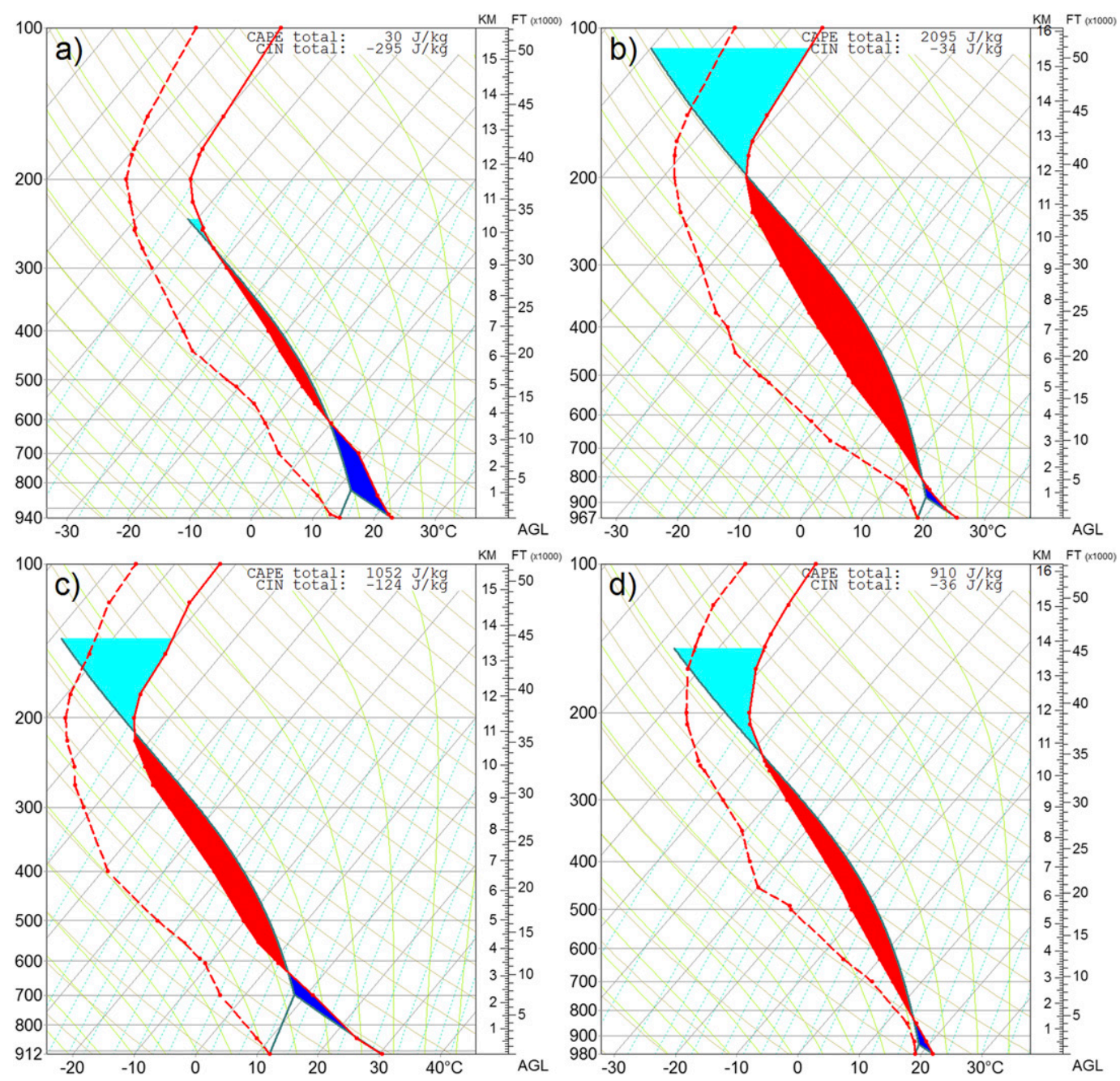

FIG. 6. Composite skew $T-\log p$ diagrams for the 57 cases with the (a) strongest (most negative) MLCIN, (b) weakest (most positive) MLCIN, (c) lowest $\mathrm{RH}_{\mathrm{Sfc}-5}$, and (d) highest $\mathrm{RH}_{\mathrm{Sfc}-5}$. Surface-based CAPE and CIN results are given at the top right of each plot, with red (blue) shading in the diagrams highlighting CAPE (CIN). Forty-five of the cases are from 0000 UTC for the strongest composite MLCIN (47 for the weakest), whereas 55 of the cases are from 0000 UTC for the lowest $\mathrm{RH}_{\mathrm{Sfc}-5}$ composite (46 for the highest).

when compared to the weakest $10 \%$ MLCIN cases (Fig. 5b). Composite soundings for the upper and lower $10 \%$ of MLCIN cases (Figs. 6a,b) show much stronger inhibition (and drier low levels) for the lowest $10 \%$ of MLCIN cases (Fig. 6a), consistent with a more "elevated" storm in these situations that is not ingesting the easterly surface winds (e.g., Corfidi et al. 2008).

The low $\mathrm{RH}_{\text {Sfc-5 }}$ composite sounding (Fig. 6c) and composite hodograph (Fig. 7b) are suggestive of environments that are conducive to enhanced outflow owing to evaporatively driven downdrafts. Indeed, the observed storm motion is biased $1.2 \mathrm{~m} \mathrm{~s}^{-1}$ faster than predicted by both methods (Table 4). The low $\mathrm{RH}_{\text {Sfc-5 }}$ composite sounding also features relatively strong inhibition (cf. Figs. 6a,c), possibly making the storm somewhat elevated and, thus, enhancing the eastward bias of observed motion.

\section{2) SMALLEST ERRORS}

The smallest supercell motion forecast errors are evident for cases with strong observed $\mathrm{SRW}_{9-10}$, slow observed SCM and/or weak $\mathrm{MW}_{0-8} / \mathrm{MW}_{0-6}$, high $\mathrm{RH}_{\mathrm{Sfc}-5}$, and weak MLCIN (Table 4). In general, the other extreme of these variables tends to be associated with much larger errors [some of which was discussed in section $3 \mathrm{c}(1)]$.

The composite hodograph for the upper $10 \% \mathrm{SRW}_{9-10}$ (Fig. 8a) is reminiscent of the low-precipitation supercell composite from Rasmussen and Straka (1998; see their Fig. 6) by virtue of the strong upper-level 

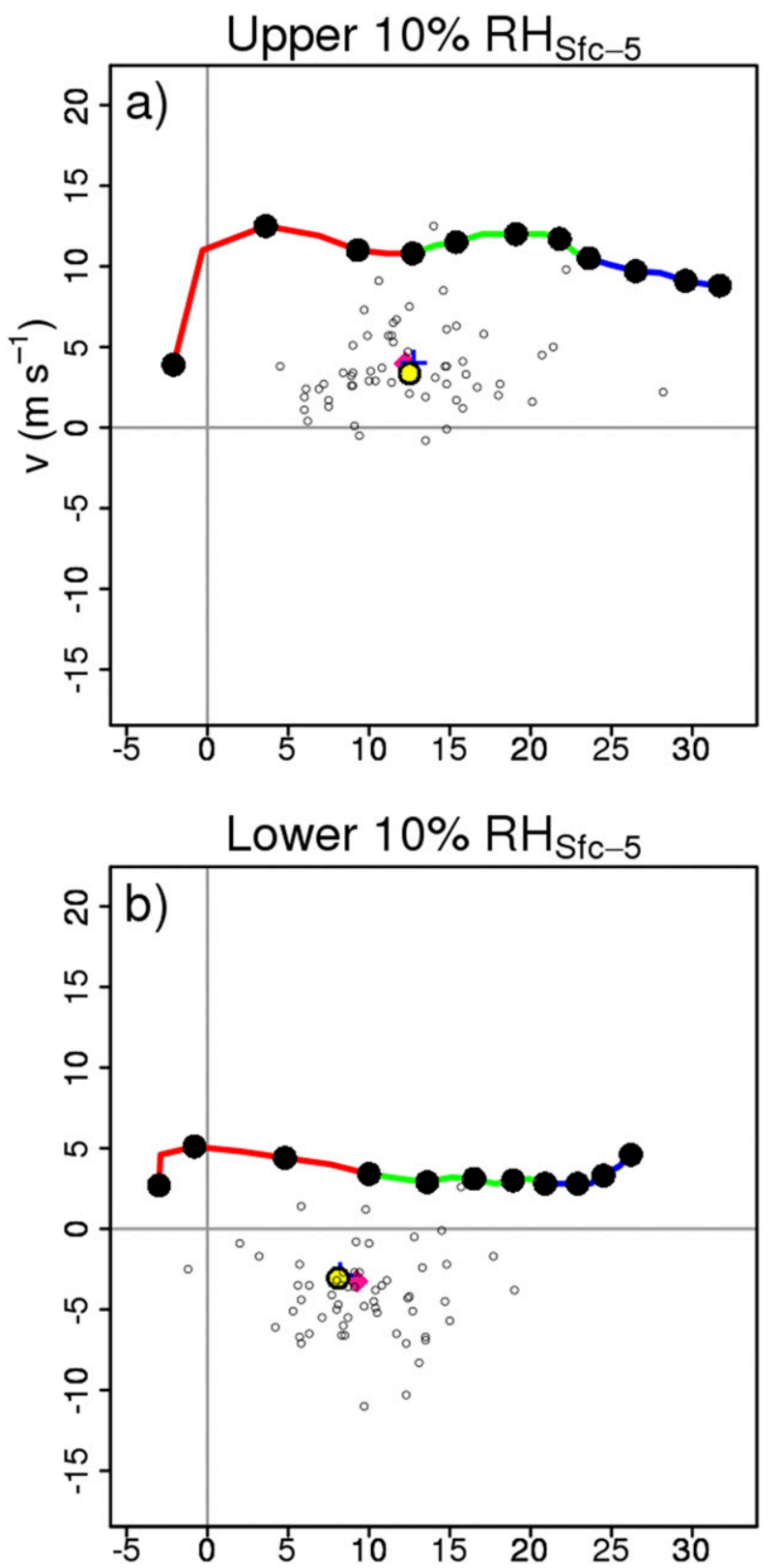

FIG. 7. As in Fig. 1, but for the 57 cases with the (a) highest $\mathrm{RH}_{\mathrm{Sfc}-5}$ and (b) lowest $\mathrm{RH}_{\mathrm{Sfc}-5}$.

winds, slight backing of the shear vectors, and location mostly in the top-right quadrant (relative to their other hodographs). MAEs and RMSEs for the upper $10 \%$ $\mathrm{SRW}_{9-10}$ are the lowest for all 17 variables for both methods, and the biases are comparatively low (Table 4); errors of $\leq 3.5 \mathrm{~m} \mathrm{~s}^{-1}$ generally are not problematic for NWS warning polygons given their typical duration of 30-45 min (e.g., $<6-\mathrm{km}$ error after $30 \mathrm{~min}$ ). These smaller MAEs are consistent with the relatively smaller supercell motion forecast errors that occur with low- versus high-precipitation supercells (e.g., RB98, $\mathrm{B} 2 \mathrm{~K})$. Moreover, the anomalous midlevel signature noted in Fig. 3 is absent from this composite.

Composite hodographs for the lower $10 \%$ observed SCM (Fig. 8b) and lower $10 \% \mathrm{MW}_{0-6}$ and $\mathrm{MW}_{0-8}$ (Figs. 8c,d) are associated with storm motions that have a south-to-southeast component and are relatively well predicted with small overall MAEs and biases (Table 4); however, the forecasts for the lower $10 \%$ $\mathrm{MW}_{0-6}$ and $\mathrm{MW}_{0-8}$ partitions have a tendency to be a little too far to the right of the observed. These hodographs are similar to the composite for the bottom-left partition discussed earlier (Fig. 1c) and also have backing upper-level shear vectors. Therefore, for these more "atypical" hodographs with slow and/or southerly storm motions, the forecast supercell motions by $\mathrm{B} 2 \mathrm{~K}$ or RB98mod are reasonably good and reliable (i.e., a likely benefit of these methods' Galilean invariance).

Most of the thermodynamic variables did not result in substantially large or small errors; however, high $\mathrm{RH}_{\mathrm{Sfc}-5}$ tends to be associated with relatively small supercell motion forecast errors (Table 4; second smallest for both B2K and RB98mod). The difference in the MAEs between the lower $10 \%$ and upper $10 \% \mathrm{RH}_{\mathrm{Sfc}-5}$ is most pronounced for the $\mathrm{B} 2 \mathrm{~K}$ method (i.e., a $0.7 \mathrm{~m} \mathrm{~s}^{-1}$ reduction for the upper $10 \%$ ). The composite hodograph for the upper $10 \%$ $\mathrm{RH}_{\mathrm{Sfc}-5}$ partition appears typical for supercell environments (Fig. 7a), and even though the midlevel winds are relatively weak, the hodograph does not exhibit the supposed problematic midlevel structure shown in Fig. 3.

MLCIN is another thermodynamic variable that is associated with relatively small storm motion errors for cases with small inhibition (i.e., the upper $10 \%$ MLCIN; see Table 4). These results for the upper $10 \%$ MLCIN partition are essentially opposite to those for the lower $10 \%$ MLCIN partition [refer to the end of section 3c(1)]. Thus, these cases with weak inhibition (Fig. 6b) lead to storms that are more likely to be surface based and, hence, the surface wind directly influences the supercell motion as prescribed by the forecast methods.

\section{d. Observations of the 30 cases with the smallest and largest errors}

As a final check to gauge the representativeness of the above results, the 30 cases with the best and worst forecasts from both methods were evaluated. The composite hodographs for the best 30 cases are similar between the B2K and RB98mod methods (Figs. 9a,b); both have slight counterclockwise curvature of the shear vectors aloft with relatively modest low-level shear magnitude (also noted in Fig. 8). The MAEs are $0.6-0.7 \mathrm{~m} \mathrm{~s}^{-1}$ with biases of $0.10-0.15 \mathrm{~m} \mathrm{~s}^{-1}$, indicating 

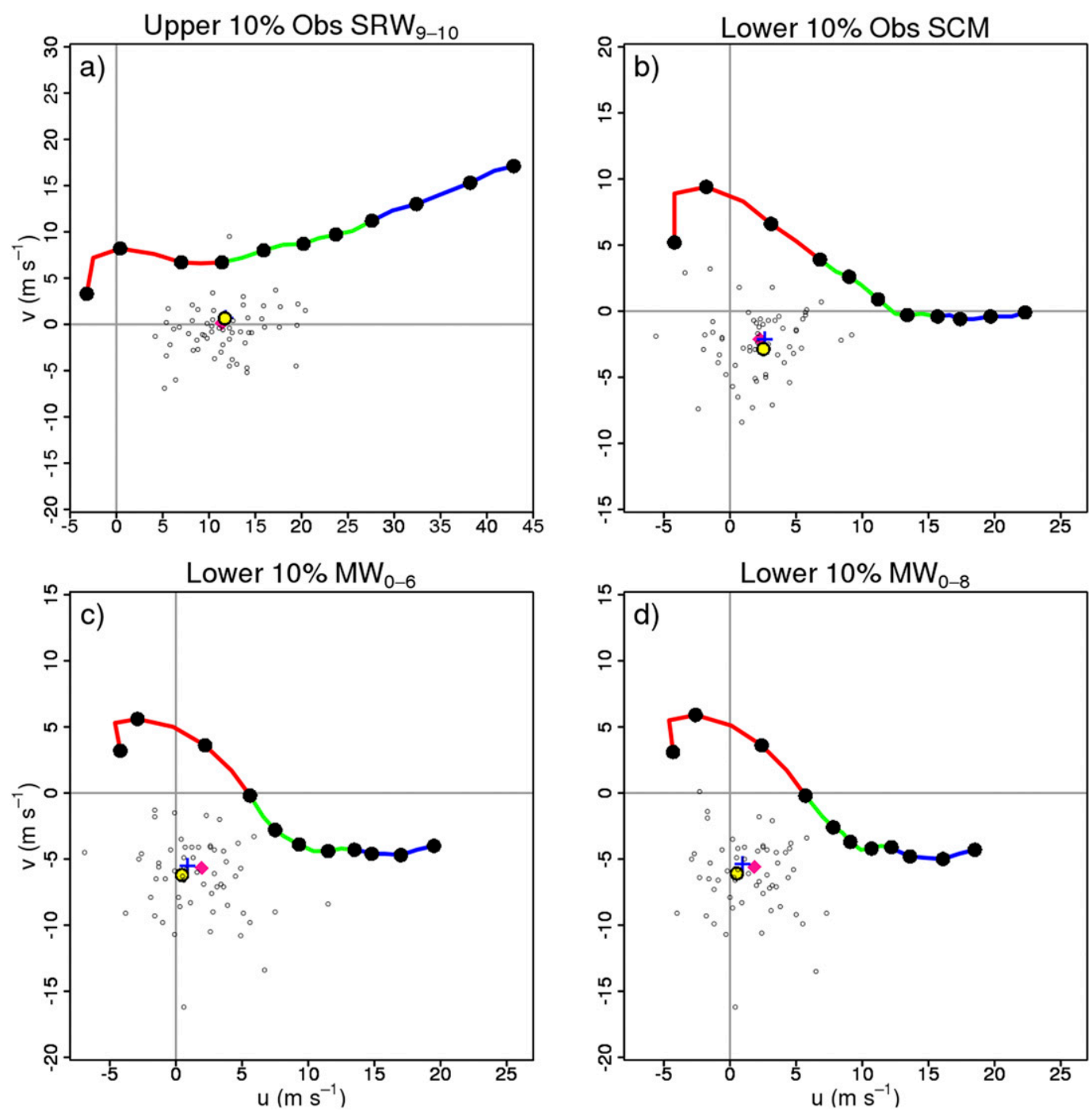

FIG. 8. As in Fig. 1, but for the 57 cases with the (a) strongest observed $\mathrm{SRW}_{9-10}$, (b) slowest observed SCM, (c) weakest $\mathrm{MW}_{0-6}$, and (d) weakest $\mathrm{MW}_{0-8}$.

that the methods are quite similar for the bestperforming cases.

The composite hodographs for the worst 30 cases highlight a few of the features noted in section $3 \mathrm{c}(1)$. First, the relatively large low-level shear and/or hodograph curvature (Figs. 9c,d) is consistent with Fig. 4a for the upper $10 \%$ observed $\mathrm{SRH}_{0-3}$; the observed motion is biased $2.7-3.7 \mathrm{~m} \mathrm{~s}^{-1}$ to the east-southeast (faster than predicted). Second, there is a lack of consistent veering of the upper-level shear vectors, which was shown to be problematic in Fig. 3. The MAEs are $8.1 \mathrm{~m} \mathrm{~s}^{-1}$ for B2K and $9.5 \mathrm{~m} \mathrm{~s}^{-1}$ for RB98mod.

Regarding the thermodynamic variables, the strongest signal is with the MLCIN. For the best-performing cases, the average MLCIN ranges from -34 to $-54 \mathrm{~J} \mathrm{~kg}^{-1}$, and for the worst-performing cases the average is $-80 \mathrm{~J} \mathrm{~kg}^{-1}$. Otherwise, the average MLLFC is 427-622 $\mathrm{m}$ lower than the MLLFC for the best-performing cases versus the worst-performing cases. Despite this MLLFC result, differences in the various RH layers are minimal $(<3 \%$ difference between the best and worst cases).

Finally, the variability of the storm motions for the worst 30 cases is much greater than for the best 30 cases (cf. top and bottom rows in Fig. 9). This variability cannot be attributed to hodograph differences alone; rather, much of this variability could be related to external storm factors that cannot be accounted for by a hodograph, such as boundary-storm interactions, merging storms, and surging outflows (e.g., Browning 1965; Weaver 1979; Maddox et al. 1980; Weaver and Nelson 1982; Zehr and 

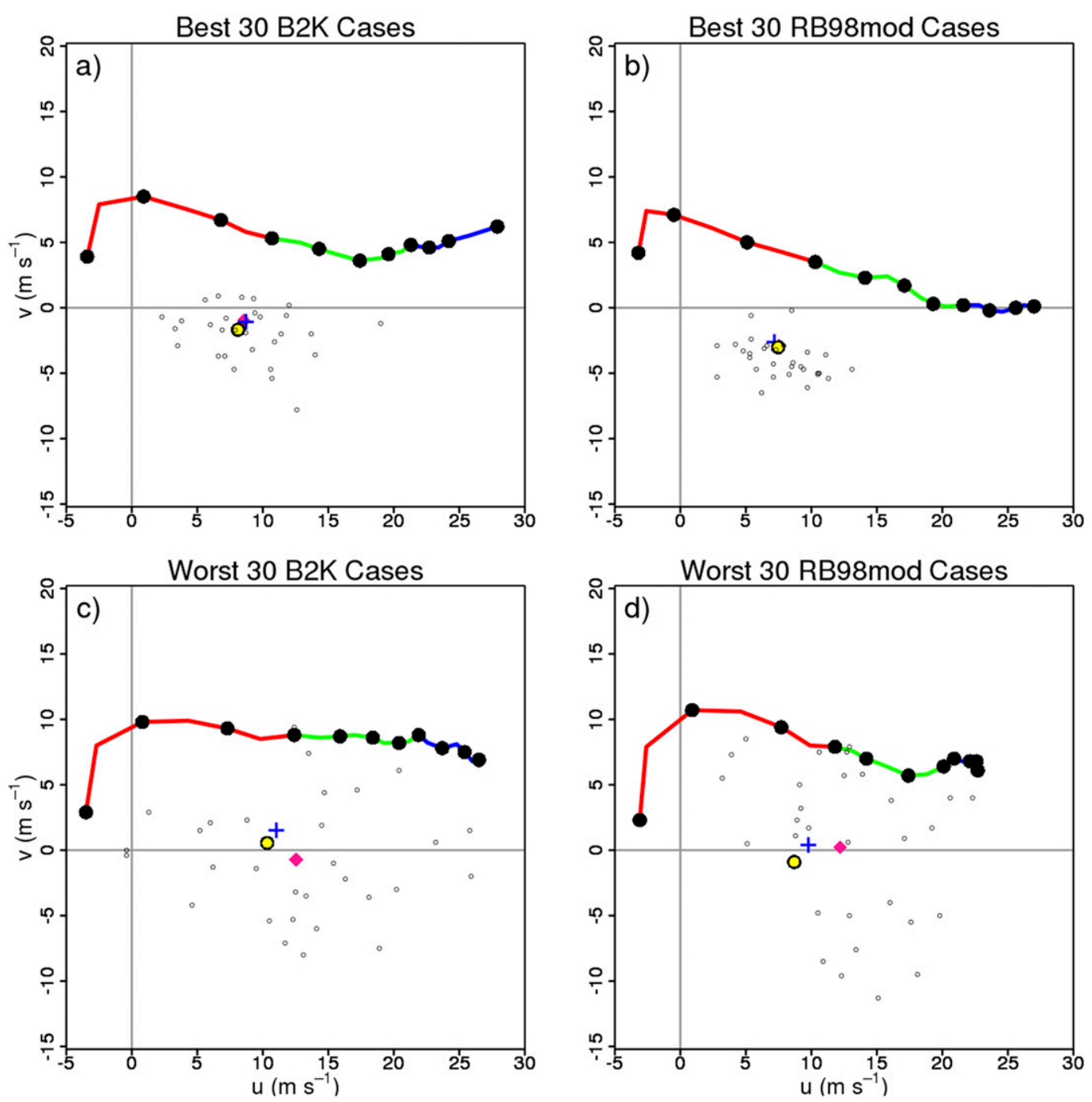

FIG. 9. As in Fig. 1, but for the 30 cases with the (a) best B2K forecast, (b) best RB98mod forecast, (c) worst B2K forecast, and (d) worst RB98mod forecast.

Purdom 1982; Markowski et al. 1998; Atkins et al. 1999; Zeitler and Bunkers 2005). All of these studies imply that storms will move differently in the presence of these mesoscale disturbances than they would be expected to move using techniques that fail to account for these mesoscale influences. This is an area where operational forecasters have the greatest opportunity to improve upon hodograph-based storm motion forecasts.

\section{Conclusions}

Two well-known, Galilean-invariant, supercell motion forecast methods were evaluated using a 573-case observed right-moving supercell dataset to understand how they perform under varying environmental and storm constraints. Although predicting supercell motion amounts to more than just a simple interpretation of a hodograph, some common themes emerged as to when to be more or less confident in the supercell motion forecasts derived from a hodograph. Following are conclusions of this study that may be of operational use:

- Forecasters can be most confident in hodograph-based right-moving supercell motion forecasts from the B2K (or RB98mod) method when (i) hodographs are relatively straight with slight counterclockwise curvature of the shear vectors through the mid- and upper levels, (ii) convective inhibition is weak and the lowmidlevel RH is high, (iii) supercell motion is slow or the mean wind is weak, or (iv) storm motion lies toward the bottom-left quadrant of the hodograph. 
- Forecasters should have the least confidence in hodograph-based right-moving supercell motion forecasts from the B2K (or RB98mod) method when (i) there is a counterclockwise kink to the hodograph in the mid- to upper levels; (ii) the low-level shear is strong and the shear vectors curve clockwise by $\geq 90^{\circ}$ in the lowest $3 \mathrm{~km}$, leading to large $\mathrm{SRH}_{0-3}$; (iii) convective inhibition is strong and low-midlevel $\mathrm{RH}$ is low; or (iv) supercell motion is fast. In addition, the observed supercell motion is biased slower and to the right of the B2K method for significantly tornadic supercells (generally consistent with the findings for large $\mathrm{SRH}_{0-3}$ ).

One thing that confounds these results is that opposing conditions can be present at the same time (e.g., high $\mathrm{RH}_{\mathrm{Sfc}-5}$ but large $\mathrm{SRH}_{0-3}$; slow supercell motion but strong inhibition). However, the situations producing the least confidence seem to have straightforward biases (e.g., large SRH leads to farther off-hodograph deviation than predicted; low RH, strong inhibition, and fast supercell motion lead to a faster motion than predicted; a midlevel "kink" leads to increased variability in storm motion). Moreover, recognizing that a supercell is deviating farther to the right of the predicted motion potentially could be an indicator of strong low-level shear/streamwise vorticity and, thus, perhaps increased tornadic potential.

Finally, these results do not suggest that one should move away from using the $\mathrm{B} 2 \mathrm{~K}$ method in its current applications. Rather, one should be cognizant of the B2K method's strengths and weaknesses so that the method can be applied properly.

Acknowledgments. The author thanks Dave Hintz (meteorologist-in-charge, NWS, Rapid City, SD) for supporting this work, Drs. Adam French and Darren Clabo (South Dakota School of Mines and Technology) for early reviews of the manuscript, Jeff Manion (NWS Central Region) for a technical evaluation prior to submitting the manuscript for review, Dr. Erik Rasmussen and two anonymous reviewers for several suggestions for improvement and clarification, and Phil Schumacher (NWS, Sioux Falls, SD) for providing training on RStudio (https://www.rstudio.com/). RStudio was used to create the hodographs and perform the statistical tests herein.

\section{REFERENCES}

Atkins, N. T., M. L. Weisman, and L. J. Wicker, 1999: The influence of preexisting boundaries on supercell evolution. Mon. Wea. Rev., 127, 2910-2927, https://doi.org/10.1175/1520-0493(1999) 127<2910:TIOPBO >2.0.CO;2.

Banacos, P. C., and H. B. Bluestein, 2004: Hodograph variability within analytically modeled, synoptic-scale, baroclinic systems. Mon. Wea. Rev., 132, 1448-1461, https://doi.org/10.1175/ 1520-0493(2004)132<1448:HVWAMS>2.0.CO;2.
Brown, R. A., 1993: A compositing approach for preserving significant features in atmospheric profiles. Mon. Wea. Rev., 121, 874-880, https://doi.org/10.1175/1520-0493(1993)121<0874: ACAFPS $>2.0 . \mathrm{CO} ; 2$.

Browning, K. A., 1965: The evolution of tornadic storms. J. Atmos. Sci., 22, 664-668, https://doi.org/10.1175/1520-0469(1965) 022<0664:TEOTS $>2.0$. CO;2.

Bunkers, M. J., B. A. Klimowski, J. W. Zeitler, R. L. Thompson, and M. L. Weisman, 2000: Predicting supercell motion using a new hodograph technique. Wea. Forecasting, 15, 61-79, https:// doi.org/10.1175/1520-0434(2000)015<0061:PSMUAN > 2.0.CO;2.

—, J. S. Johnson, L. J. Czepyha, J. M. Grzywacz, B. A. Klimowski, and M. R. Hjelmfelt, 2006: An observational examination of long-lived supercells. Part II: Environmental conditions and forecasting. Wea. Forecasting, 21, 689-714, https://doi.org/10.1175/WAF952.1.

— J. R. Wetenkamp Jr., J. J. Schild, and A. Fischer, 2010: Observations of the relationship between $700-\mathrm{mb}$ temperatures and severe weather reports across the contiguous United States. Wea. Forecasting, 25, 799-814, https://doi.org/10.1175/ 2009WAF2222333.1.

_ D. A. Barber, R. L. Thompson, R. Edwards, and J. Garner, 2014: Choosing a universal mean wind for supercell motion prediction. J. Oper. Meteor., 2 (11), 115-129, https://doi.org/ 10.15191/nwajom.2014.0211.

Corfidi, S. F., S. J. Corfidi, and D. M. Schultz, 2008: Elevated convection and castellanus: Ambiguities, significance, and questions. Wea. Forecasting, 23, 1280-1303, https://doi.org/ 10.1175/2008WAF2222118.1.

Craven, J. P., R. E. Jewell, and H. E. Brooks, 2002: Comparison between observed convective cloud-base heights and lifting condensation level for two different lifted parcels. Wea. Forecasting, 17, 885-890, https://doi.org/10.1175/ 1520-0434(2002)017<0885:CBOCCB $>2.0 . \mathrm{CO} ; 2$

Davies-Jones, R., 2002: Linear and nonlinear propagation of supercell storms. J. Atmos. Sci., 59, 3178-3205, https://doi.org/ 10.1175/1520-0469(2003)059<3178:LANPOS > 2.0.CO;2.

Doswell, C. A., III, H. E. Brooks, and N. Dotzek, 2009: On the implementation of the enhanced Fujita scale in the USA. Atmos. Res., 93, 554-563, https://doi.org/10.1016/ j.atmosres.2008.11.003.

Finch, J., and D. Bikos, 2010: A long-lived tornadic supercell over Colorado and Wyoming, 22 May 2008. Electron. J. Severe Storms Meteor., 5 (5), http://www.ejssm.org/ojs/index.php/ ejssm/issue/view/23.

Grant, L. D., and S. C. Van den Heever, 2014: Microphysical and dynamical characteristics of low-precipitation and classic supercells. J. Atmos. Sci., 71, 2604-2624, https://doi.org/10.1175/ JAS-D-13-0261.1.

Harrison, D. R., and C. D. Karstens, 2017: A climatology of operational storm-based warnings: A geospatial analysis. Wea. Forecasting, 32, 47-60, https://doi.org/10.1175/WAF-D-15-0146.1.

Johns, R. H., 1984: A synoptic climatology of northwest-flow severe weather outbreaks. Part II: Meteorological parameters and synoptic patterns. Mon. Wea. Rev., 112, 449-464, https:// doi.org/10.1175/1520-0493(1984)112<0449:ASCONF>2.0.CO;2.

Kirkpatrick, J. C., E. W. McCaul Jr., and C. Cohen, 2007: The motion of simulated convective storms as a function of basic environmental parameters. Mon. Wea. Rev., 135, 3033-3051, https://doi.org/10.1175/MWR3447.1.

MacIntosh, C. W., and M. D. Parker, 2017: The 6 May 2010 elevated supercell during VORTEX2. Mon. Wea. Rev., 145, 2635-2657, https://doi.org/10.1175/MWR-D-16-0329.1. 
Maddox, R. A., L. R. Hoxit, and C. F. Chappell, 1980: A study of tornadic thunderstorm interactions with thermal boundaries. Mon. Wea. Rev., 108, 322-336, https://doi.org/10.1175/ 1520-0493(1980)108<0322:ASOTTI >2.0.CO;2.

Markowski, P. M., E. N. Rasmussen, and J. M. Straka, 1998: The occurrence of tornadoes in supercells interacting with boundaries during VORTEX-95. Wea. Forecasting, 13, 852-859, https:// doi.org/10.1175/1520-0434(1998)013<0852:TOOTIS>2.0.CO;2.

- , C. Hannon, J. Frame, E. Lancaster, A. Pietrycha, R. Edwards, and R. L. Thompson, 2003: Characteristics of vertical wind profiles near supercells obtained from the Rapid Update Cycle. Wea. Forecasting, 18, 1262-1272, https://doi.org/ 10.1175/1520-0434(2003)018<1262:COVWPN >2.0.CO;2.

Nielsen, E. R., G. R. Herman, R. C. Tournay, J. M. Peters, and R. S. Schumacher, 2015: Double impact: When both tornadoes and flash floods threaten the same place at the same time. Wea. Forecasting, 30, 1673-1693, https://doi.org/10.1175/WAF-D-15-0084.1.

Nowotarski, C. J., P. M. Markowski, and Y. P. Richardson, 2011: The characteristics of numerically simulated supercell storms situated over statically stable boundary layers. Mon. Wea. Rev., 139, 3139-3162, https://doi.org/10.1175/MWR-D-10-05087.1.

NWS, 2011: NWS Central Region service assessment: Joplin, Missouri, tornado - May 22, 2011. NOAA/NWS Central Region Headquarters, 41 pp., https:/www.weather.gov/media/ publications/assessments/Joplin_tornado.pdf.

Parker, M. D., 2014: Composite VORTEX2 supercell environments from near-storm soundings. Mon. Wea. Rev., 142, 508529, https://doi.org/10.1175/MWR-D-13-00167.1.

Potvin, C. K., K. L. Elmore, and S. J. Weiss, 2010: Assessing the impacts of proximity sounding criteria on the climatology of significant tornado environments. Wea. Forecasting, 25, 921-930, https://doi.org/10.1175/2010WAF2222368.1.

Ramsay, H. A., and C. A. Doswell III, 2005: A sensitivity study of hodograph-based methods for estimating supercell motion. Wea. Forecasting, 20, 954-970, https://doi.org/10.1175/ WAF889.1.

Rasmussen, E. N., and D. O. Blanchard, 1998: A baseline climatology of sounding-derived supercell and tornado forecast parameters. Wea. Forecasting, 13, 1148-1164, https://doi.org/ 10.1175/1520-0434(1998)013<1148:ABCOSD>2.0.CO;2.

_, and J. M. Straka, 1998: Variations in supercell morphology. Part I: Observations of the role of upper-level storm-relative flow. Mon. Wea. Rev., 126, 2406-2421, https://doi.org/10.1175/ 1520-0493(1998)126<2406:VISMPI >2.0.CO;2.
Thompson, R. L., R. Edwards, J. A. Hart, K. L. Elmore, and P. Markowski, 2003: Close proximity soundings within supercell environments obtained from the Rapid Update Cycle. Wea. Forecasting, 18, 1243-1261, https://doi.org/10.1175/ 1520-0434(2003)018<1243:CPSWSE > 2.0.CO;2.

- C. M. Mead, and R. Edwards, 2007: Effective storm-relative helicity and bulk shear in supercell thunderstorm environments. Wea. Forecasting, 22, 102-115, https://doi.org/10.1175/ WAF969.1.

— B. T. Smith, J. S. Grams, A. R. Dean, and C. Broyles, 2012: Convective modes for significant severe thunderstorms in the contiguous United States. Part II: Supercell and QLCS tornado environments. Wea. Forecasting, 27, 1136-1154, https:// doi.org/10.1175/WAF-D-11-00116.1.

Warren, R. A., H. Richter, H. A. Ramsay, S. T. Siems, and M. J. Manton, 2017: Impact of variations in upper-level shear on simulated supercells. Mon. Wea. Rev., 145, 2659-2681, https:// doi.org/10.1175/MWR-D-16-0412.1.

Weaver, J. F., 1979: Storm motion as related to boundary-layer convergence. Mon. Wea. Rev., 107, 612-619, https://doi.org/ 10.1175/1520-0493(1979)107<0612:SMARTB >2.0.CO;2.

—, and S. P. Nelson, 1982: Multiscale aspects of thunderstorm gust fronts and their effects on subsequent storm development. Mon. Wea. Rev., 110, 707-718, https://doi.org/10.1175/ 1520-0493(1982)110<0707:MAOTGF >2.0.CO;2.

Weisman, M. L., and J. B. Klemp, 1984: The structure and classification of numerically simulated convective storms in directionally varying wind shears. Mon. Wea. Rev., 112, 2479-2498, https://doi.org/10.1175/1520-0493(1984)112<2479: TSACON $>2.0 . \mathrm{CO} ; 2$.

- and R. Rotunno, 2000: The use of vertical wind shear versus helicity in interpreting supercell dynamics. J. Atmos. Sci., 57, 1452-1472, https://doi.org/10.1175/1520-0469(2000)057<1452: TUOVWS $>2.0$.CO;2.

Wilks, D. S., 2011: Statistical Methods in the Atmospheric Sciences. 3rd ed. Elsevier, 676 pp.

Zehr, R. M., and J. F. W. Purdom, 1982: Examples of a wide variety of thunderstorm propagation mechanisms. Preprints, 12th Conf. on Severe Local Storms, San Antonio, TX, Amer. Meteor. Soc., 499-502.

Zeitler, J. W., and M. J. Bunkers, 2005: Operational forecasting of supercell motion: Review and case studies using multiple datasets. Natl. Wea. Dig., 29, 81-97, http://nwafiles.nwas.org/ digest/papers/2005/Vol29No1/Pg81-Zeitler.pdf. 